\title{
Subclinical Hypothyroidism During Valproic Acid Therapy in Children with Epilepsy
}

\author{
Dhananjoy Das ${ }^{1 *}$ \\ Meah Monjur Ahmed ${ }^{2}$ \\ Pranab Kumar Chowdhury ${ }^{3}$ \\ Pradip Kumar Dutta ${ }^{4}$ \\ M A Chowwdhury ${ }^{1}$
}

\author{
${ }^{1}$ Department of Paediatric Neurology \\ Chattagram Maa-O-Shishu Hospital Medical College \\ Chittagong, Bangladesh. \\ ${ }^{2}$ Department of Paediatrics \\ Mohichail 20 Beded Hospital \\ Chandina, Comilla, Bangladesh. \\ ${ }^{3}$ Department of Paediatrics \\ Chittagong Medical College \\ Chittagong, Bangladesh. \\ ${ }^{4}$ Department of Nephrology, \\ Chittagong Medical College \\ Chittagong, Bangladesh.
}

*Correspondence to:

\section{Dr. Dhananjoy Das}

Assistant Professor

Department of Paediatric Neurology

Chattagram Maa-O-Shishu Hospital Medical College

Chittagong, Bangladesh.

Mobile : +8801819859016

Email : dhananjoyjoly@gmail.com

www.banglajol.info/index.php/CMOSHMCJ

\begin{abstract}
Background : Valproic Acid (VPA) is an effective anticonvulsant widely used for the treatment of epilepsy in children, but there are pitfalls in VPA therapy, especially in case of various endocrine organs like thyroid. So the aim of this study was to evaluate the thyroid dysfunction in terms of subclinical hypothyroidism during Valproic Acid (VPA) therapy in children with epilepsy. Methods: The study was conducted in the Department of Paediatrics, and Shishu Bikas Kendra, Chittagong Medical College Hospital $(\mathrm{CMCH})$ over one year duration on 50 newly diagnosed idiopathic epileptic children who were decided to start Valproate at the dose of $20 \mathrm{mg} / \mathrm{kg} /$ day. At the same time similar number $(\mathrm{n}=50)$ of age and sex matched children visited the paediatric OPD for other health events(e.g. acute upper respiratory infection, Influenza like illness and Acute watery diarrhoea) other than epilepsy were included in the study as control group. Thyroid function status like serum levels of Thyroid-Stimulating Hormone (TSH) Free Triiodothyronine $\left(\mathrm{FT}_{3}\right)$ and Free Thyroxin $\left(\mathrm{FT}_{4}\right)$ were evaluated at baseline and after six months. Moreover, serum VPA level was also measured in children receiving valproate at follow up visit. Anti thyroid peroxidise antibody (Anti TPO ab) was checked at follow up visit in those having TSH level beyond normal reference range. After collecting all data it was analyzed by SPSS-19. Results: In the current study, cases consisted of 30(60\%) male and 20(40\%) female children. Male to female ratio was 1.5:1. Gender and age were matched in cases and control group ( $>0.05$ ). Most of the population in the cases were from rural areas $29(58 \%)$ and most of them $40(80 \%)$ belonged to middle class family. The mean \pm SD of TSH level significantly increased after six months in comparison with base line values $(1.76 \pm 0.57 \mu \mathrm{IU} / \mathrm{ml}$ vs. $2.70 \pm 1.50 \mu \mathrm{IU} / \mathrm{ml}, \mathrm{p}<0.05)$ and with control group at follow up visit $(1.74 \pm 0.73 \mu \mathrm{IU} / \mathrm{ml}$ vs $2.70 \pm 1.50 \mu \mathrm{IU}$, $\mathrm{p}<0.05)$. On the other hand, in the control group there were no significant changes of TSH level in comparison with base line $(1.82 \pm 0.55 \mu \mathrm{IU}$ vs $1.74 \pm 0.73 \mu \mathrm{IU} / \mathrm{ml}$, $\mathrm{p}=0.16$ ). The mean $\pm \mathrm{SD}$ of $\mathrm{FT}_{4}$ value decreased significantly in the cases after six months though remained within normal reference range $(1.24 \pm 0.27 \mathrm{ng} / \mathrm{dl}$ $\mathrm{vs} 1.11 \pm 0.13 \mathrm{ng} / \mathrm{dl}, \mathrm{p}<0.05) \mathrm{FT}_{3}$ level remained unchanged. Five $(10 \%)$ epileptic children in the cases were found to have subclinical hypothyroidism at follow up who had TSH level beyond the normal reference range. Anti thyroid peroxidase antibody was negative among them. In contrast, no one in control group was found to have TSH level beyond the normal limit. All cases were clinically euthyroid. No significant correlations were found between TSH level and serum VPA level $\left(\mathrm{r}^{2}=\right.$ $0.035 \mathrm{p}=0.193)$. Conclusion: Subclinical hypothyroidism develops in children with epilepsy during VPA therapy. Proper attention should be given so that development of overt hypothyroidism can be avoided.
\end{abstract}

Key words: Valproate; Hypothyroidism; Thyroid stimulating hormone. 


\section{INTRODUCTION}

Seizure is a common neurological disorder in the pediatric age group as it occurs in $10 \%$ of them. Less than one third of seizures that occur in children are due to epilepsy ${ }^{1}$. Seizure is a transient occurrence of signs and or symptoms resulting from abnormal, excessive or synchronous neuronal activity in the brain $^{2}$. Epilepsy is a disorder of brain characterized by an enduring predisposition to generate seizure and by the neurobiological, cognitive, psychological and social consequence of this condition ${ }^{2}$.

The incidence of epilepsy is $3 \%$ it is a common neurological morbidity in children worldwide, $80 \%$ of whom live in developing countries ${ }^{2}$. In Bangladesh epidemiological surveys confirm that seizure disorders are common, one study showing prevalence rate of seizure is 68 out of every one thousand for 'any seizure history' and nine out of every one thousand for 'any unprovoked seizure' in children aged 2-9 years ${ }^{3}$.

Valproate (VPA) is the most commonly used drugs in the treatment of epilepsy. Valproate is a branched chain fatty acid. It has broad spectrum of antiepileptic efficacy in the treatment of both partial and generalized seizures, but it is a drug of choice in primary generalized epilepsy ${ }^{4,5,6}$. Its mechanism of action are believed to be result from combination of multiple mechanisms. It inhibits repetitive firing of neurons by inhibiting voltage sensitive sodium channels and at high concentrations it activate calcium dependent potassium conductance.VPA also has a GABAergic effect through elevation of GABA levels in the brain ${ }^{7}$.

Thyroid diseases are usually presented as a spectrum of clinical and metabolic features of varying severity. Many exogenous and endogenous factors may affect thyroid function, these include the pathway of thyroid hormone biosynthesis, secretion, transport and metabolism which offer numerous targets for drug interaction ${ }^{8-11}$. Interaction between the endocrine systems, epilepsy and AEDs are complex. Epilepsy per se may affect the hormonal balance and hormone may have affect on seizure activity. AEDs can change circulating hormone concentrations ${ }^{12}$.

Different thyroid dysfunctions have been reported in epileptic patient receiving VPA. Report on the effect of VPA on thyroid hormone balance are conflicting, both low and unchanged serum $\mathrm{T}_{4}$ and $\mathrm{FT}_{4}$ levels, normal or high TSH levels have been found in patients receiving VPA monotherapy ${ }^{1}$. VPA induced thyroid dysfunction is not well established, inhibition of somatostatin a potential inhibitor of TSH secretion via a Gamma Aminobuteric Acidergic (GABA) effect has been proposed as a basic mechanism. Zinc and selenium deficiency are the other suggestions but the evidence is insufficient ${ }^{13}$. Various endocrine effects including thyroid dysfunction during treatment of this drug are well documented. Kim et al in their prospective case control study found that the incidence of subclinical hypothyroidism in patients with VPA therapy was $52.4 \%{ }^{13}$.
Talebian A et al. in their observational study found that, the serum level of TSH significantly increased in VPA treated patients, $\mathrm{T}_{4}$ level decreased in CBZ and VPA treated patients, level of $\mathrm{FT}_{3}$ significantly decreased only in VPA treated patients. $\mathrm{FT}_{4}$ level decreased significantly only in patients treated with $\mathrm{CBZ}^{1}$.

A prospective study on thirty-two newly diagnosed paediatric patients with epilepsy was performed by Verroti Alberto et al and found that base line thyroid function was normal in all patients. After three months of CBZ therapy $\mathrm{TT}_{4}$ and $\mathrm{FT}_{4}$ significantly decreased than base line. Serum $\mathrm{T}_{4}$ and $\mathrm{FT}_{4}$ were unaffected by VPA monotherapy. Serum $\mathrm{T}_{3}$ and $\mathrm{FT}_{3}$ were normal in both CBZ and VPA treated patients. There were no changes in TSH level ${ }^{14}$.

Considering the facts in these studies, $\mathrm{T}_{4}$ and $\mathrm{FT}_{4}$ are consistently low in patients receiving $\mathrm{CBZ}$ while $\mathrm{FT}_{3}$ and $\mathrm{TSH}$ are normal. Conflicting results are found in epileptic patients receiving VPA as monotherapy. Some studies found high TSH value and normal serum thyroxin level some studies revealed no alteration in thyroid functions. So aim of the current study is to assess the effects of VPA on thyroid function status.

\section{MATERIALS AND METHODS}

Children aged 2-12 years, diagnosed as idiopathic epilepsy in the Department of Paediatrics (Inpatients \& outpatients) and Shishu Bikash Kendra of $\mathrm{CMCH}$, naive to anticonvulsant decided to start VPA as monotherapy at the dose of $20 \mathrm{mg} / \mathrm{kg} /$ day were the cases, which were initially 58 in number. At the same time equal number of age and sex matched children attended to paediatric OPD for other health events e.g. acute upper respiratory infections, influenza like illness and acute watery diarrhea other than epilepsy were included as control group. After initial screening, the legal guardians of the subjects were explained about the aims, objectives and procedure of the study. After getting informed written consent from them a blood sample was collected for initial thyroid function tests, $\mathrm{TSH}, \mathrm{FT}_{3}$ and $\mathrm{FT}_{4}$. If result found within normal limit the subject was followed up again after six months. Among the 58 cases five patients did not come in follow up and three patients were to need to increase the dose of drug. So finally study was completed with 50 cases and 50 controls. At follow up visit another blood sample was collected for analysis of thyroid status $\mathrm{FT}_{3}, \mathrm{FT}_{4} \& \mathrm{TSH}$, and also the serum level of VPA. Clinical findings regarding thyroid abnormalities and other associated findings like socio-demographic information, seizure history, and birth history, family history of seizure, developmental assessment, neurological examination and anthropometric assessment were also noted. In control group initially thyroid screening (TSH, $\mathrm{FT}_{3}$ and $\mathrm{FT}_{4}$ ) was done and another screening performed just after six months to compare the results. Patients who had TSH level beyond the reference range at follow up visit, Anti TPO antibody was assessed to exclude autoimmune thyroiditis. For biochemical tests, $10 \mathrm{cc}$ 
venous bloods were collected by a trained laboratory technologist. After mixing suitable anticoagulant blood sample was send to the selected laboratory. Reagents and kits were collected earlier by the researcher himself. Assay technique was acquired by researcher himself and a technologist and all tests were measured by Automated Chemiluminescent Immunoassay system. The normal reference range of $\mathrm{TSH}, \mathrm{FT}_{3}$ and $\mathrm{FT}_{4}$ were $0.35-5.0 \mu \mathrm{IU} / \mathrm{ml}, 1.5-4.2 \mathrm{pg} / \mathrm{ml}$, and $0.65-2.3 \mathrm{ng} / \mathrm{dl}$ respectively. Therapeutic range of VPA was $50-100 \mathrm{mcg} / \mathrm{ml}$. All relevant data was taken in a pretested data sheet and data was analyzed by computer based software SPSS-19.

\section{RESULTS}

Among the 100 study population boy were $65(65 \%)$ and girl were $35(35 \%)$. Male to female ratio was 1.8:1. Gender was matched in study subjects and control group $(p=0.834)$. Most of the subject in the cases and in control group were from rural area $29(58 \%)$ and $26(52 \%)$ respectively.

In terms of analysis of the socioeconomic condition of the study population most of them were from upper middle class $27(54 \%)$ and $30(60 \%)$ respectively.

Generalized seizure were found in $42(84 \%)$ of cases and $8(16 \%)$ were with focal seizure. Out of 42 patients with generalized seizure, $30(60 \%)$ patients had tonic clonic seizure, $6(12 \%)$ tonic seizure, $3(6 \%)$ clonic seizure, $2(4 \%)$ absence seizures and $1(2 \%)$ myoclonic seizure. Out of 8 patients with focal seizure, $2(4 \%)$ had complex partial seizure and $6(12 \%)$ had secondary generalized seizure.

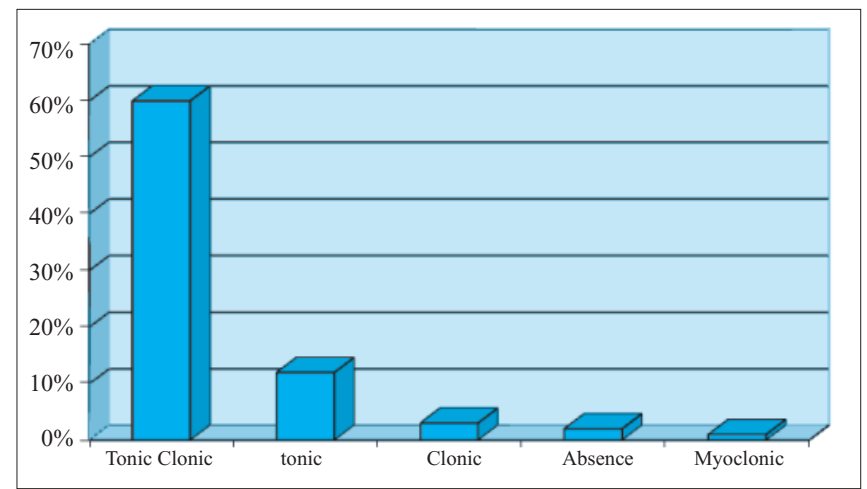

Figure 1 : Type of Generalized seizure

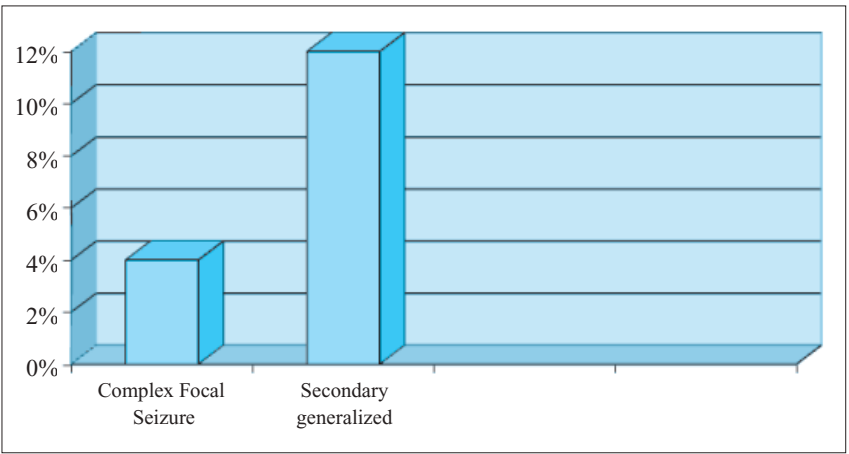

Figure 2 : Type of Focal seizure
Among the control group Acute Upper Respiratory Infection (AURI) comprises of $35(70 \%)$, Influenza like illness 5(10\%) Acute watery diarrhoea $10(20 \%)$. Subject belongs to AURI, $21(60 \%)$ had common cold, $5(14.3 \%)$ had acute ear infection, $7(20 \%)$ had acute pharyngotonsillitis and $2(5.7 \%)$ had acute sinusitis.

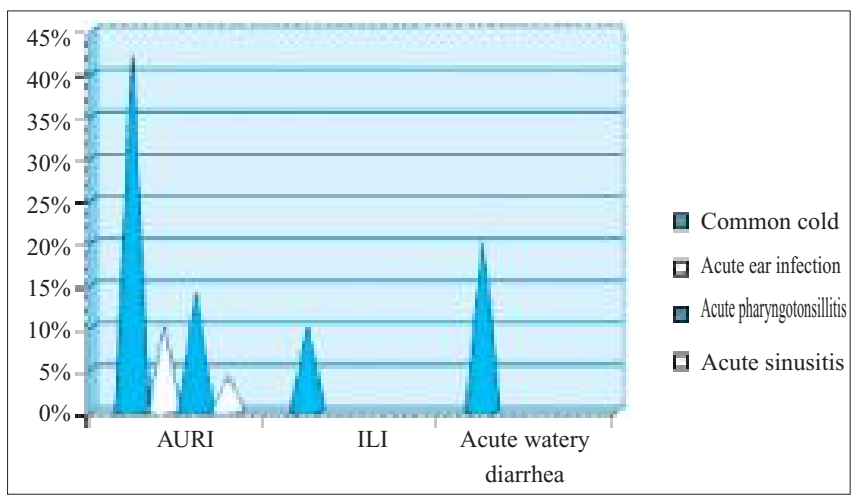

Figure 3 : Categories of control group

TSH level significantly increased after six months in comparison to baseline $(\mathrm{p}<0.05)$ among cases. Among control group it was found insignificant $(p>0.05)$. There was no significant correlation found between the valproic acid level and TSH, $\mathrm{FT}_{3}, \mathrm{FT}_{4}$ level after 6 months of treatment.

Table 1: Comparison of $\mathrm{TSH}, \mathrm{FT}_{3}$, and $\mathrm{FT}_{4}$ at baseline and at follow up visit

\begin{tabular}{lccccc} 
Hormones & \multicolumn{2}{c}{ Case $(\mathrm{n}=\mathbf{5 0})$} & \multicolumn{2}{c}{ Control $(\mathrm{n}=50)$} & p-value* \\
& Mean & Std. Deviation Mean & Std. Deviation & \\
TSH base line $(\mu \mathrm{IU} / \mathrm{ml})$ & 1.7672 & 0.57362 & 1.8240 & 0.55412 & 0.616 \\
TSH six months later( $(\mu \mathrm{I} / \mathrm{ml})$ & 2.7080 & 1.50730 & 1.7453 & 0.73398 & 0.000 \\
$\mathrm{FT}_{3}$ base line $(\mathrm{pg} / \mathrm{ml})$ & 3.0348 & 0.39284 & 3.0750 & 0.67432 & 0.716 \\
$\mathrm{FT}_{3}$ six months later( $(\mathrm{pg} / \mathrm{ml})$ & 3.0448 & 0.50043 & 3.1474 & 0.64300 & 0.375 \\
$\mathrm{FT}_{4}$ base line(ng/dl) & 1.2422 & 0.27539 & 1.1648 & 0.30977 & 0.190 \\
$\mathrm{FT}_{4}$ six months later(ng/dl) & 1.1102 & 0.13460 & 1.1622 & 0.39423 & 0.380
\end{tabular}

*p value was calculated by independent sample $t$ test

Table 2 : Paired $t$ test significance of $\mathrm{TSH}, \mathrm{FT}_{3}$ and $\mathrm{FT}_{4}$ within the cases

\begin{tabular}{llrrr} 
& & Mean & Std. Deviation & p value \\
Pair 1 & TSH base line $(\mu \mathrm{IU} / \mathrm{ml})$ & 1.7672 & 0.57362 & 0.000 \\
& TSH six months later $(\mu \mathrm{IU} / \mathrm{ml})$ & 2.7080 & 1.50730 & \\
Pair 2 & $\mathrm{FT}_{3}$ base line $(\mathrm{pg} / \mathrm{ml})$ & 3.0348 & 0.39284 & 0.883 \\
& $\mathrm{FT}_{3}$ six months later $(\mathrm{pg} / \mathrm{ml})$ & 3.0448 & 0.50043 & \\
Pair 3 & $\mathrm{FT}_{4}$ base line $(\mathrm{ng} / \mathrm{dl})$ & 1.2422 & 0.27539 & 0.003 \\
& $\mathrm{FT}_{4}$ six months later(ng/dl) & 1.1102 & 0.13460 & \\
\hline
\end{tabular}

Table 3 : Paired $t$ test significance of $\mathrm{TSH}_{2} \mathrm{FT}_{3}$ and $\mathrm{FT}_{4}$ within the control group

\begin{tabular}{llrrr} 
& & Mean & Std. Deviation & p value \\
Pair 1 & TSH base line $(\mu \mathrm{IU} / \mathrm{ml})$ & 1.8240 & 0.55412 & 0.167 \\
& TSH six months later $(\mu \mathrm{IU} / \mathrm{ml})$ & 1.7453 & 0.73698 & \\
Pair 2 & $\mathrm{FT}_{3}$ base line $(\mathrm{pg} / \mathrm{ml})$ & 3.0750 & 0.67432 & 0.287 \\
& $\mathrm{FT}_{3}$ six months later $(\mathrm{pg} / \mathrm{ml})$ & 3.1474 & 0.64300 & \\
Pair 3 & $\mathrm{FT}_{4}$ base line(ng/dl) & 1.1648 & 0.30977 & 0.901 \\
& $\mathrm{FT}_{4}$ six months later(ng/dl) & 1.1622 & 0.39423 & \\
\hline
\end{tabular}




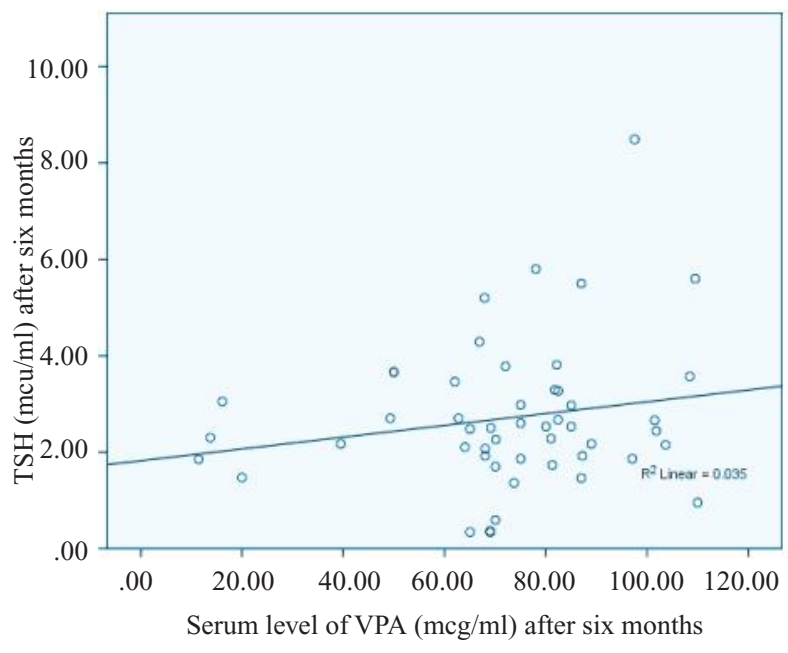

Figure 3 : Correlation between serum valproic acid level and TSH level Pearson correlation $=0.187$, $\mathrm{p}$-value $=0.193$

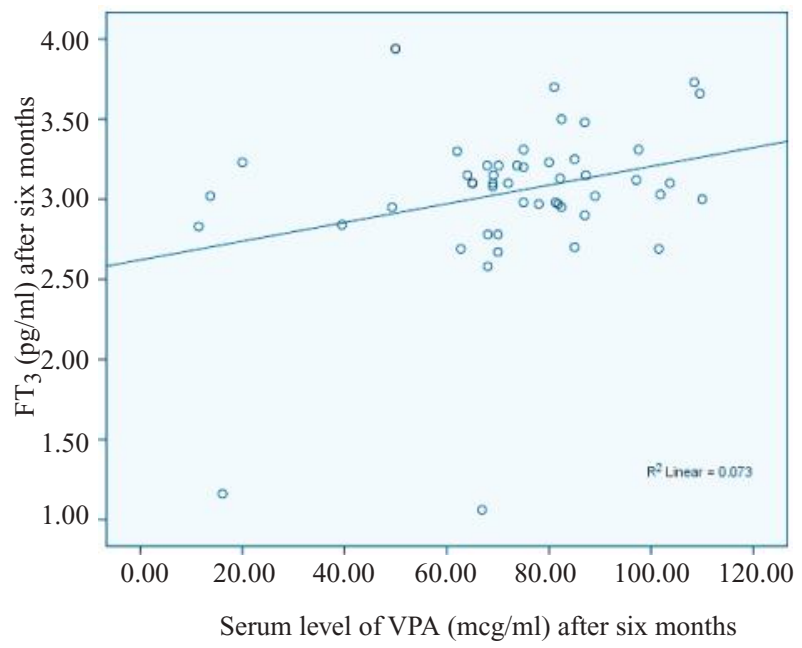

Figure 4 : Correlation between serum valproic acid level and $\mathrm{FT}_{3}$

Pearson correlation $=0.270, \mathrm{p}$ value $=0.058$

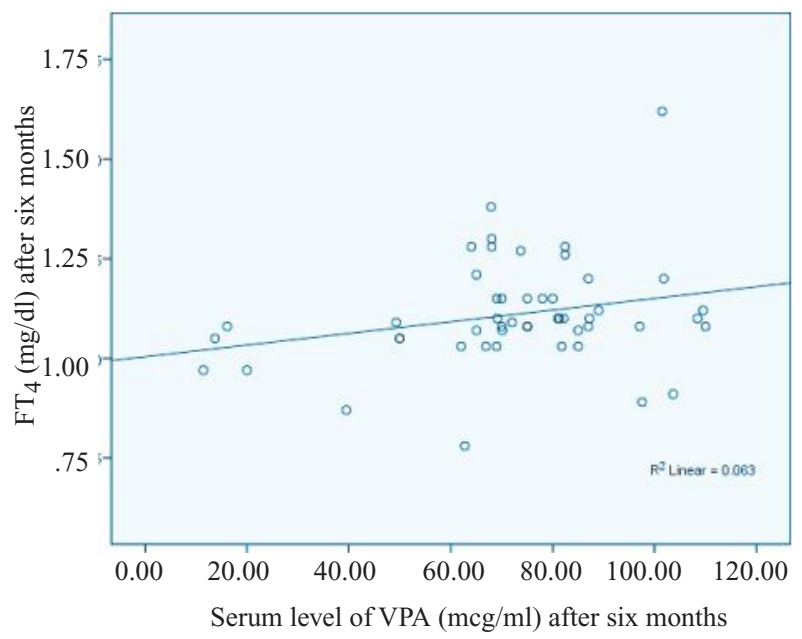

Figure 5 : Correlation between serum valproic acid level and $\mathrm{FT}_{4}$

Pearson correlation $=0.123$, $\mathrm{p}$-value $=0.396$

\section{DISCUSSION}

Sodium valproate is the most commonly used drug in the treatment of epilepsy ${ }^{6}$. It has broad spectrum anti epileptic efficacy in the treatment of both partial and generalized epilepsy. Various endocrine effects including thyroid dysfunction during the treatment with this drug are well documented $^{1}$. In the earlier studies no significant change in thyroid hormone concentration were observed during VPA therapy, but alteration of thyroid function status have been demonstrated in recent studies ${ }^{15,16}$.

This is a cohort study, performed on newly diagnosed idiopathic epileptic children who were prescribed valproate at a dose of $20 \mathrm{mg} / \mathrm{kg} / \mathrm{day}$. It was found that $5(10 \%)$ out of 50 patients had subclinical hypothyroidism at follow up after six months from the starting of treatment. No one in control group was found to have subclinical hypothyroidism. This percentage seems to be a little lower compared with the $52 \%$ by Kim et al $25.5 \%$ by Eiris-Punal et al and $25.1 \%$ by Mikati et al ${ }^{13,16,17}$. This difference seems to occur due to different definitions of normal TSH level (TSH $=0.35-5.0 \mu \mathrm{IU} / \mathrm{ml}$ in this study). The definition of normal TSH level has long been debated and TSH level seems to vary widely in different populations and according to different study methods ${ }^{18}$. Ethnicity or area where the study was performed may be other explanations for this difference. A higher prevalence of thyroid dysfunction in the Korean population has been noted in different studies using different situations ${ }^{13}$. Further studies are needed to determine whether the effects of VPA therapy on thyroid function vary according to ethnicity. This difference may also result from large sample size or different study methods eg. cross sectional comparative study, where base line thyroid status is unknown.

This current study revealed that the mean \pm SD level of TSH at follow up after six months significantly increased in comparison with base line value $(1.76 \pm 0.57 \mu \mathrm{IU} / \mathrm{ml}$ vs $2.70 \pm 1.50 \mu \mathrm{IU} / \mathrm{ml}, \mathrm{p}<0.05)$ which is also true for control group $(1.74 \pm 0.73 \mu \mathrm{IU} / \mathrm{ml}$ vs $2.70 \pm 1.50 \mu \mathrm{IU} / \mathrm{ml} \mathrm{p}<0.05)$. Level of $\mathrm{FT}_{3}$ remained unchanged but the mean $\pm \mathrm{SD}$ of $\mathrm{FT}_{4}$ level significantly decreased after six months from the base line $(1.24 \pm 0.27 \mathrm{ng} / \mathrm{dl}$ vs $1.11 \pm 0.13 \mathrm{ng} / \mathrm{dl}, \mathrm{p}<0.05)$ though still within normal reference range. This result is in agreement with study carried out by Kim et $\mathrm{al}^{13}$. Where they found that mean serum TSH level were significantly increased compared with control group. In this study serum total $\mathrm{T}_{3}$ level significantly decreased but $\mathrm{FT}_{4}$ were not significantly different from control group. They enrolled epileptic children receiving valproate more than six months with different doses and compared thyroid function with follow up result after one year. They also performed anti TPO anti body in all patients to exclude autoimmune thyroiditis, which showed negative results. They identified that high dose of VPA and high serum level of VPA act as a risk factor for the development of subclinical hypothyroidism. 
Present study result is consistent with the study by Eiris Punnel et $\mathrm{al}^{16}$. This showed that $26 \%$ of epileptic patients having subclinical hypothyroidism received VPA therapy from 12 months to 161 months. $\mathrm{FT}_{4}$ level was significantly lower than that of the control group.

Previous study conducted by Cansu et $\mathrm{al}^{19}$. On newly diagnosed epileptic children receiving Oxcarbazepine (OXC) or Valproate (VPA) revealed that $\mathrm{TT}_{4}, \mathrm{FT}_{4}, \mathrm{TT}_{3}, \mathrm{FT}_{3}$ decreased significantly after six months compared with base line in patients treated with OXC. Mean TSH level increased significantly and $\mathrm{FT}_{3}$, $\mathrm{FT}_{4}, \mathrm{TT}_{4}$ remained similar in patients receiving valproate which is in agreement with present study. They also assessed Thyroid Releasing Hormone (TRH) stimulation test, anti TPO ab, reverse triidothyronine $\left(\mathrm{rT}_{3}\right)$ urinary iodide level which remained normal throughout the study. Doses of drugs were according to guidelines.

Present study result is in accordance with previous study by Donery et al who found that TSH level increased significantly and $\mathrm{FT}_{4}$ level decreased compared with baseline values and control group ${ }^{20} . \mathrm{FT}_{3}$ level remained unchanged. TSH \& $\mathrm{FT}_{4}$ level were within normal reference range. They enrolled newly diagnosed patients with idiopathic epilepsy who were prescrived VPA as monotherapy with the dose of $20 \mathrm{mg} / \mathrm{kg} /$ day. Current study result is not in accordance with Verrotti et al who studied thyroid function test in different stages i.e. at the $3^{\text {rd }}$, $6^{\text {th }}$, and $12^{\text {th }}$ month after the initiation of treatment with CBZ or VPA in patients with newly diagnosed epilepsy ${ }^{14}$. They found no significant alteration of thyroid function status except $T_{4}$, $\mathrm{FT}_{4}$ level which significantly decreased at the $3^{\text {rd }}$ month in patients receiving CBZ. Anti TPO-ab and anti TG-ab were always absent in all patients. TRH test responses were normal. Sample size in this study was very small $(n=32)$ and only 18 patients were treated with $\mathrm{CBZ}$ and 14 patients were treated with VPA.

In this current study thyroid hormones showed no significant correlation with serum valproic acid level. This result is in disagreement with previous result which revealed that TSH had significant positive correlation with the dose of VPA, duration of treatment and serum valproic acid level ${ }^{13}$. In their study patients were enrolled with different doses and duration, but in the present study doses were fixed, which indicates that change in thyroid hormone concentration is not related to the doses of valproate.

All patients in the present study were found to be clinically euthyroid in comparison with base line except deterioration of school performance which may be the result of epilepsy itself as seizure causes apoptosis of neurons. This result is not consistent with the previous result which found scoring of symptom and sign of hypothyroidism increased significantly compared with control group in patients with long term treatment with different antiepileptic drugs like CBZ, VPA, and PHT more than six months to five years ${ }^{21}$. Scoring of symptom and sign of hypothyroidism significantly increased in patients treated with VPA and scoring of symptom and sign increased more in polytherapy than in monotherapy. This study also found significant positive correlation between TSH level, and duration of treatment \& scoring of symptom and sign of hypothyroidism. So duration of drug intake may explain the present study result.

In this study Anti TPO ab was found negative in five cases, who had TSH level beyond normal reference range which is consistent with the previous study ${ }^{13,19}$. This finding suggests that increased TSH level is not resulting from autoimmune thyroiditis.

In this study the mean age of cases and control group was 6.33 years and 5.77 years respectively. Most of the patients in the cases were male $(60 \%)$ which suggest epilepsy is more common in male than female as indicated in the other study ${ }^{3}$. $42(84 \%)$ of cases were found to have Generalized epilepsy and $8(16 \%)$ were focal epilepsy which indicates generalized epilepsy is common in paediatric age group. Most of the population in the cases and control group belonged to rural area $(58 \% \& 52 \%)$ and middle class family. As more patients from rural area are referred by general physician to the tertiary hospital like $\mathrm{CMCH}$ and usually most of the time they belong to middle class family.

Some reports suggest that though antiepileptic drugs like CBZ and PHT have been found to induce hypothyroidism due to their hepatic enzyme induction properties which lead to increased clearance of thyroid hormones, valproate do not have the same effect on thyroid function as it is not a hepatic enzyme inducer $^{21,22}$.

The mechanisms of VPA-induced thyroid dysfunction are not well established. Inhibition of somatostatin, a potential inhibitor of TSH secretion, via an -aminobutyric acidergic effect has been proposed as a basic mechanism. Zinc and selenium deficiencies are other suggestions, but the evidence is insufficient ${ }^{13,21}$.

Several long-term studies have shown that treating subclinical hypothyroidism decreases the risk for overt hypothyroidism, improves hyperlipidemia, and reverses cognitive or psychiatric changes in asymptomatic individuals. Based on these facts, screening of the general population for subclinical hypothyroidism has been advocated by some endocrinologists ${ }^{21,23,24-27}$. This issue remains under debate, mainly because of its cost-effectiveness and inconclusive results. In contrast, regular screening of TSH level in certain high-risk populations is supported by various groups, with replacement of $\mathrm{T}_{4}$ being recommended in subjects with an elevated TSH level $(>10 \mathrm{IU} / \mathrm{mL})^{22,27,28}$. There is no consensus on the management of VPA associated subclinical hypothyroidism because of lack of data. However, follow-up of these patients would be beneficial to determine whether they develop overt hypothyroidism or other related adverse effects subsequently. 


\section{LIMITATIONS}

There are some limitations observed in this study. Thyroid hormones were not measured during a fixed time of the day. For ethical reasons, we could not include a control group with epilepsy without any treatment. Moreover TRH stimulation test could not be performed which might give idea about mild or early stage of subclinical hypothyroidism.

\section{CONCLUSION}

Subclinical hypothyroidism occurs during VPA therapy that may benefit from thyroid function screening to prevent overt hypothyroidism.

\section{DISCLOSURE}

All the authors declared no competing interest.

\section{REFERENCES}

1. Talebian A, Eslamian MR, Shiasi K, Moravveji A, khodayari M, Abedi AR. Changing in thyroid function test in children underwent antiepileptic therapy. Iran J child Neurology. 2010;4(1):17-22.

2. Mikati MA. Seizures in childhood. In: Kliegman RM, Stanton BF, Schor NF, Geme JW, Behrman RE, editors. Nelson textbook of pediatrics. $19^{\text {th }}$ ed. Philadelphia: Saunders and Elsevier. 2008;2013-2014.

3. Banu SH, Khan NZ, Hossain M, Jahan A, Rahman N, Boyd SH et al. Profile of childhood epilepsy in Bangladesh. Developmental Medicine \& child neurology. 2003; 45:477-482.

4. Luhdorf k, Jensen Lk, Plesner AM. Etiology of the seizures in the elderly. Epilepsia. 1989; 458-463.

5. Rogvi-Hansen B, Gram L. Adverse effects of established and new antiepileptic drugs: An attempted comparison. Pharmacology \& therapeutics. 1995;3:425-434.

6. Davis R, Peters DH, McTavish D. Valproic acid a reappraisal of its pharmacological properties and clinical efficacy in epilepsy. Drugs. 1994;2:332-327.

7. Maclean MJ, Macdonald RL. Sodium valproate, but not ethosuxiimide, produces use and voltage dependent limitation of high frequency repetitive firing of action potentials of mouse central neurons in cell culture. Journal of pharmacology \& Experimental therapeutics. 1986;237(3):1001-1011.

8. Shorvon S. Handbook of epilepsy treatment. Oxford: Blackwell science LTD. 2000;90-99.

9. Isojarvi JI, Laatikainen TJ, Knip M, Pakarinen AJ, Juntunen KT, Myllyla VV. Obesity and endocrine disorders in women taking valproate for epilepsy. Annals of neurology. 1996;5:579-584.

10. Desai MP. Thyroid function in children. Supplement to Japi. 2011;59:35-42.

11. Ahmed AH, Thanoon IA, Effect of carbamazepine and valproic acid monotherapy on thyroid function tests in epileptic patients. Ann coll Med mosul. 2006;32(1\&2):57-62.

12. Isojarvi JT, Pakarinen AJ, Myllyla VV. Thyroid function in epileptic patients treated with carbamazepine. Arch Neurol. 1989;45:1175-1178.

13. Kim SH, Chung HR, Kim SH, Kim H, Lim BC, Chae JH et al. Subclinical hypothyroidism during valproic acid therapy in children and adolescents with epilepsy. Neuropediatrics. 2012;43:135-139.

14. Verrotti A, Laus M, Scardapane A, Franzoni E, Chiarelli F. Thyroid hormones in children with epilepsy during long term administration of carbamazepine and valproate. European society of Endocrinology. 2009;160:81-86.

15. Vainionpää LK, Mikkonen K, Rättyä J, Knip M, Pakarinen AJ, Myllyla VV et al. Thyroid function in girls with epilepsy with carbamazepine, oxcarbazepine, or valproate monotherapy and after withdrawal of medication. Epilepsia. 2004;45(3):197-203.

16. Eirís-Puñal J, DelRío-Garma M, DelRío-Garma MC, Lojo-Roca-monde S, Novo-Rodríguez I, Castro-Gago M. Long-term treatment of children with epilepsy with valproate or carbamazepine may cause subclinical hypothyroidism. Epilepsia. 1999; 40(12):1761-1766.

17. Mikati MA, Tarabay H, Khalil A, Rahi AC, El Banna D, Najjar S. Risk factors for development of subclinical hypothyroidism during valproic acid therapy. J Pediatr. 2007;151(2):178-181. 


\section{REFERENCES}

18. Rastogi N, Aggarwal A, Mittal H, Patil R, Chillar N. Evaluation of thyroid function in epileptic children on carbamazepine or valproate therapy. Paediatric neurology. 2011; 45(3):159-162.

19. Cansu A, Serdaro lu A, Çamurdan O, Hirfano lu T, Bideci A, Gücüyener K. The evaluation of thyroid functions, thyroid antibodies, and thyroid volumes in children with epilepsy during short-term administration of oxcarbazepine and valproate. Epilepsia. 2006;47(11):1855-1859.

20. Donery H, Kara IS, Karakoc A, Tan H, Orbac Z. Serum thyroid hormone profile and trace elements in children receiving valproic acid therapy: A longitudinal and controlled study. J Trace Elem Med Bio. 2012;1:5-9.

21. Yehia MA, Ahmad SF, Omar AE, EL-Bakey AO, Helmy AK, Zanaty MM. Antiepileptic drugs and risk of subclinical hypothyroidism. Egypt J Neurol Psychiat Neurosurg. 2012;49(2):131-135.

22. Gharib H, Tuttle RM, Baskin HJ, Fish LH, Singer PA, McDermott MT. Subclinical thyroid dysfunction: A joint statement on management from the American Association of Clinical Endocrinologists, the American Thyroid Association, and the Endocrine Society. J Clin Endocrinol Metab. 2005;90(1):581-587.

23. Childhood neurodevelopmental disorders workshop. New Delhi: India habitat centre. 2014;79-88.

24. Chen HS, Wu TE, Jap TS, Lu RA, Wang ML, Chen RL et al. Subclinical hypothyroidism is a risk factor for nephropathy and cardiovascular diseases in type 2 diabetic patients. Diabet Med. 2007;24:1336-1344.

25. Jung CH, Sung KC, Shin HS, Rhee EJ, Lee WY, Kim BS et al. Thyroid dysfunction and their relation to cardiovascular risk factors such as lipid profile, hsCRP, and waist hip ratio in Korea. Korean J Intern Med. 2003;18:146-153.

26. Graf WD, Oleinik OE, Glauser TA, Maertens P, Eder DN, Pippenger CE. Altered antioxidant enzyme activities in children with a serious adverse experience related to valproic acid therapy. Neuro pediatrics. 1998;29(4):195-201.

27. Surks MI, Sievert R. Drugs and thyroid function. N Engl J Med. 1995;333 (25):1688-1694.

28. Jones DD, May KE, Geraci SA. Subclinical thyroid disease. Am J Med. 2010; 123(6):502-504. 